\title{
Rational Syntheses and Structural Characterization of Sulfur-Rich Phosphorus Polysulfides: $\boldsymbol{\alpha}-\mathbf{P}_{\mathbf{2}} \mathbf{S}_{\mathbf{7}}$ and $\boldsymbol{\beta}-\mathbf{P}_{\mathbf{2}} \mathbf{S}_{\mathbf{7}} * *$
}

\author{
Thomas Rödl, Richard Weihrich, Julia Wack, Jürgen Senker, and Arno Pfitzner*
}

\section{Dedicated to Professor Roger Blachnik}

A wide range of binary compounds is known in the system phosphorus-sulfur. They consist of discrete cage-like molecules with the composition $\mathrm{P}_{4} \mathrm{~S}_{n}(n=3-10)$ except for $\mathrm{P}_{14} \mathrm{~S}^{[1]}$ The cages can formally be derived from the $\mathrm{P}_{4}$ tetrahedron of white phosphorus either by insertion of sulfur atoms into $\mathrm{P}-\mathrm{P}$ bonds or by exocyclic addition to phosphorus atoms. The maximum amount of sulfur per molecule is present in $\mathrm{P}_{4} \mathrm{~S}_{10}{ }^{[2]}$ The congruently melting phosphorus sulfides $\mathrm{P}_{4} \mathrm{~S}_{3}, \mathrm{P}_{4} \mathrm{~S}_{7}$, and $\mathrm{P}_{4} \mathrm{~S}_{10}$ are synthesized by reaction of stoichiometric amounts of the elements in the melt. ${ }^{[3]}$ Other phosphorus sulfides are not accessible by this route. For instance, $\alpha-\mathrm{P}_{4} \mathrm{~S}_{5}$ is prepared by stirring a solution of $\mathrm{P}_{4} \mathrm{~S}_{3}$, sulfur, and catalytic amounts of iodine in dry carbon disulfide at room temperature and diffuse daylight for three days. ${ }^{[4]}$ Jason used triphenylarsenic sulfide and triphenylantimony sulfide as sulfur transfer reagents in the synthesis of $\gamma-\mathrm{P}_{4} \mathrm{~S}_{6}$, for example. ${ }^{[5]}$ Another very useful sulfur transfer reagent is $\left[\left(\mathrm{CH}_{3}\right)_{3} \mathrm{Sn}\right]_{2} \mathrm{~S}{ }^{[6]}$ In contrast triphenylphosphine is suitable for the abstraction of sulfur atoms. ${ }^{[7]}$ Note that the syntheses of phosphorus sulfides often result in mixtures of different compounds. In addition, various modifications of phosphorus sulfides of the same composition are known. Unfortunately the nomenclature is far from systematic. In fact, it is a quite confusing mix of Greek letter prefixes and Roman numeral suffixes that are used to distinguish between both different constitution isomers and different crystal structures of identical cage molecules. Herein we use Greek letter prefixes, not only to distinguish between two polymorphs but also to consider the chronological order of their discovery.

As already mentioned $\mathrm{P}_{4} \mathrm{~S}_{10}$ is the most sulfur-rich phosphorus sulfide structurally characterized to date. However there is evidence for the existence of more sulfur-rich compounds $\mathrm{P}_{4} \mathrm{~S}_{n}$ with $n>10 .{ }^{[8]}$ As early as 1910 Stock suspected that $\mathrm{P}_{4} \mathrm{~S}_{10}$ was not the most sulfur-rich phosphorus sulfide at all. ${ }^{[9]}$ Démarcq prepared $\operatorname{PS}_{x}(x=3-75)$ by heating $\mathrm{P}_{4} \mathrm{~S}_{10}$ with an excess of sulfur at $300^{\circ} \mathrm{C}^{[10]}$ The corresponding

[*] T. Rödl, Dr. R. Weihrich, Prof. Dr. A. Pfitzner Institute for Inorganic Chemistry, University of Regensburg Universitätstrasse 31, 93040 Regensburg (Germany) E-mail: arno.pfitzner@chemie.uni-regensburg.de

J. Wack, Prof. Dr. J. Senker

Department for Inorganic Chemistry III, University of Bayreuth 95440 Bayreuth (Germany)

[**] This work was financially supported by the DFG within the priority program SPP 1415 (project WE 4284/3-1).

$\square$ Supporting information for this article is available on the WWW under http://dx.doi.org/10.1002/anie.201103485. solution ${ }^{31} \mathrm{P}$ NMR spectra indicated a number of novel species. He termed these compounds as "phosphorus polysulfides" or "phosphorus persulfides" implying the presence of $\mathrm{S}-\mathrm{S}$ bonds. Though the system phosphorus-sulfur has been investigated for a long time, there are no structural data of phosphorus poly-(or per-) sulfides available.

More than 150 years after the discovery of $\mathrm{P}_{4} \mathrm{~S}_{10}$ by Berzelius in 1843, we herein present the first crystal structure determinations of phosphorus polysulfides, namely $\alpha-\mathrm{P}_{2} \mathrm{~S}_{7}$ and $\beta-\mathrm{P}_{2} \mathrm{~S}_{7}$.

The structures of $\alpha-\mathrm{P}_{2} \mathrm{~S}_{7}$ and $\beta-\mathrm{P}_{2} \mathrm{~S}_{7}$ differ dramatically from those of common phosphorus sulfides. They do not consist of discrete cage-like molecules but of neutral polymeric strands featuring direct $\mathrm{S}-\mathrm{S}$ bonds. Both the polymers catena- $\mathrm{P}_{2} \mathrm{~S}_{7}$ in $\alpha-\mathrm{P}_{2} \mathrm{~S}_{7}$ and in $\beta-\mathrm{P}_{2} \mathrm{~S}_{7}$ are quite similar: each phosphorus atom is tetrahedrally surrounded by sulfur atoms. These $\mathrm{PS}_{4}$ tetrahedra share one common edge resulting in $\mathrm{P}_{2} \mathrm{~S}_{6}$ units reminiscent of the thiophosphate ion $\mathrm{P}_{2} \mathrm{~S}_{6}{ }^{2-}$ in $\mathrm{M}_{2} \mathrm{P}_{2} \mathrm{~S}_{6}(\mathrm{M}=\mathrm{Ag}, \mathrm{K}, \mathrm{Cs}) \cdot{ }^{[11]}$ These units are interconnected by sulfur atoms to form $\mathrm{P}_{2} \mathrm{~S}_{7}$ polymers, see Figure 1.

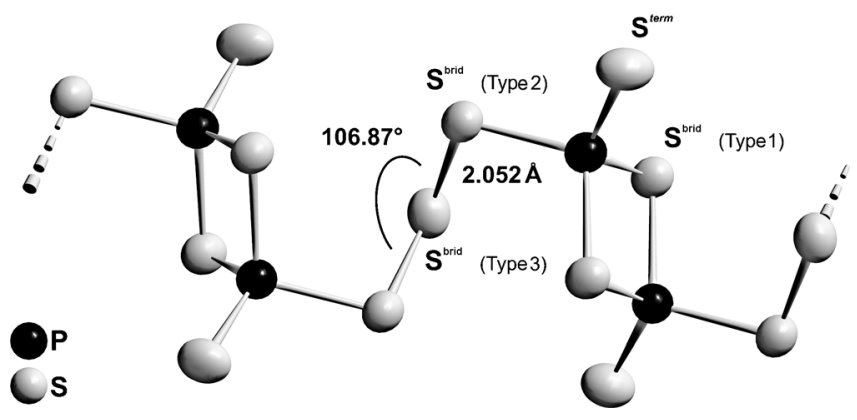

Figure 1. Section of a polymeric strand in $\alpha-P_{2} S_{7}$ featuring covalent $S-$ $\mathrm{S}$ bonds and three different types of bridging sulfur atoms. Neglecting minor deviations of bond lengths and angles, the polymers in $\beta-P_{2} S_{7}$ can be considered as identical. Ellipsoids are set at $60 \%$ probability.

The bond lengths and angles in $\alpha-\mathrm{P}_{2} \mathrm{~S}_{7}$ and $\beta-\mathrm{P}_{2} \mathrm{~S}_{7}$ differ little. As expected for phosphorus polysulfides, direct $\mathrm{S}-\mathrm{S}$ bonds are present in the form of triple (-S-S-S-) sulfur units, in which the S-S distances vary only slightly from 2.050(2) to 2.052(2) $\AA$ and are typical for a covalent S-S single bond. The angle $\chi(\mathrm{S}-\mathrm{S}-\mathrm{S})$ is $106.87(7)^{\circ}$ in $\alpha-\mathrm{P}_{2} \mathrm{~S}_{7}$ and $105.84(5)^{\circ}$ in $\beta-\mathrm{P}_{2} \mathrm{~S}_{7}$. A similar bonding situation is given in elementary sulfur $\alpha-\mathrm{S}_{8}$. The same holds for the $\mathrm{S}_{3}{ }^{2-}$ units in $\left[\left(\mathrm{TiCl}_{2}\right)\left(1,3-\mathrm{P}_{2} \mathrm{~S}_{8}\right)\right]_{2}$ with $d(\mathrm{~S}-\mathrm{S})=2.046(3)-2.057(4) \AA \quad$ and $\quad \chi(\mathrm{S}-\mathrm{S}-\mathrm{S})=108.3(2)^{\circ} .^{[12]}$ The bond lengths between phosphorus and terminal sulfur 
atoms $d\left(\mathrm{P}-\mathrm{S}^{\text {term }}\right)$ are shorter than those between phosphorus and bridging sulfur atoms $d\left(\mathrm{P}-\mathrm{S}^{\text {brid }}\right)$ as expected. They vary in the range $1.912(1) \leq d\left(\mathrm{P}-\mathrm{S}^{\text {term }}\right) \leq 1.919(2) \AA$ and $2.099(2) \leq$ $d\left(\mathrm{P}-\mathrm{S}^{\text {brid }}\right) \leq 2.122(2) \AA$, corresponding to a formal phosphorus sulfur double and single bond, respectively. Similar values are found for common phosphorus sulfides. A closer look at Figure 1 reveals that there are three different types of bridging sulfur atoms. While type 1 bridges two phosphorus atoms in the $\mathrm{P}_{2} \mathrm{~S}_{6}$ units, type 2 bridges one phosphorus and one sulfur atom, and type 3 bridges two sulfur atoms. Consequently there are three different oxidation states corresponding to the three different types of bridging sulfur atoms: -II (type 1), -I (type 2), and 0 (type 3); phosphorus has an oxidation state of $+\mathrm{V}$.

The crystallographic data for $\alpha-P_{2} S_{7}$ and $\beta-P_{2} S_{7}$ are summarized in Table 1. As already mentioned the constitution of the polymers in the alpha and in the beta modification is identical. So what makes the difference? Figure 2 shows

Table 1: Crystallographic data for $\alpha-P_{2} S_{7}$ and $\beta-P_{2} S_{7}$.

\begin{tabular}{llll}
\hline Compound & & $\alpha-\mathrm{P}_{2} \mathrm{~S}_{7}$ & $\beta-\mathrm{P}_{2} \mathrm{~S}_{7}$ \\
\hline Crystal system & & monoclinic & triclinic \\
Space group & & $P 2_{1} / c($ No. 14) & $P \overline{1}($ No. 2) \\
Lattice constants ${ }^{[a]}[\AA]$ and $\left[{ }^{\circ}\right]$ & $a$ & $6.526(2)$ & $6.032(3)$ \\
& $b$ & $10.817(4)$ & $6.512(2)$ \\
& $c$ & $12.580(3)$ & $11.095(5)$ \\
& $\alpha$ & & $82.62(4)$ \\
& $\beta$ & $93.24(2)$ & $89.20(5)$ \\
Volume $\left[\AA^{3}\right], Z$ & $\gamma$ & & $85.28(4)$ \\
& $V$ & $886.6(4), 4$ & $430.7(3), 2$ \\
\hline
\end{tabular}

[a] Refined from powder data.

sections of the crystal structures of $\alpha-\mathrm{P}_{2} \mathrm{~S}_{7}$ and $\beta-\mathrm{P}_{2} \mathrm{~S}_{7}$ along and perpendicular to the polymeric strands. It becomes clear that the polymers in both compounds run parallel to each other, but the arrangements differ. Hence, this finding is a matter of packing polymorphism. Whereas $\alpha-\mathrm{P}_{2} \mathrm{~S}_{7}$ features a hexagonal (honeycomb) rod packing, the polymers in $\beta-\mathrm{P}_{2} \mathrm{~S}_{7}$ are arranged with the motif of a tetragonal rod packing. Although the arrangement of the polymers in the solid state is quite different, see Figure 2, both modifications have short interpolymeric distances $d(\mathrm{~S} \cdots \mathrm{S}) \approx 3.3 \AA$, which is far below the sum of the van der Waals radii, about $3.6 \AA$. These distances are observed both between $\mathrm{S}^{\text {term }}$ of one polymer and $S^{\text {brid }}$ (type 1) of the adjacent polymer and between $S^{\text {term }}$ and $S^{\text {brid }}$ (type 3 ), respectively. $S^{\text {brid }}$ (type 2 ) shows only interpolymeric distances close to the van der Waals distance, about $3.55 \AA$ for both modifications. The calculated densities $\rho_{\mathrm{X} \text {-ray }}$ $\left(\alpha-\mathrm{P}_{2} \mathrm{~S}_{7}\right)=2.145 \mathrm{~g} \mathrm{~cm}^{-3}$ and $\rho_{\mathrm{X} \text {-ray }} \quad\left(\beta-\mathrm{P}_{2} \mathrm{~S}_{7}\right)=2.208 \mathrm{~g} \mathrm{~cm}^{-3}$ reveal that the tetragonal packing is slightly denser. Though the difference is moderate, note that in general a perfect

Figure 2. Sections of the crystal structures of a,b) $\alpha-P_{2} S_{7}$ and c,d) $\beta$ $\mathrm{P}_{2} \mathrm{~S}_{7}$ with view parallel to the polymer axis and perpendicular to the polymer axis, respectively. Whereas $\alpha-P_{2} S_{7}$ features a hexagonal (honeycomb) rod packing, $\beta-\mathrm{P}_{2} \mathrm{~S}_{7}$ shows a tetragonal rod packing. Dashed lines represent short inter-polymeric distances, with $d(\mathrm{~S} \cdots \mathrm{S}) \approx 3.3 \AA$.
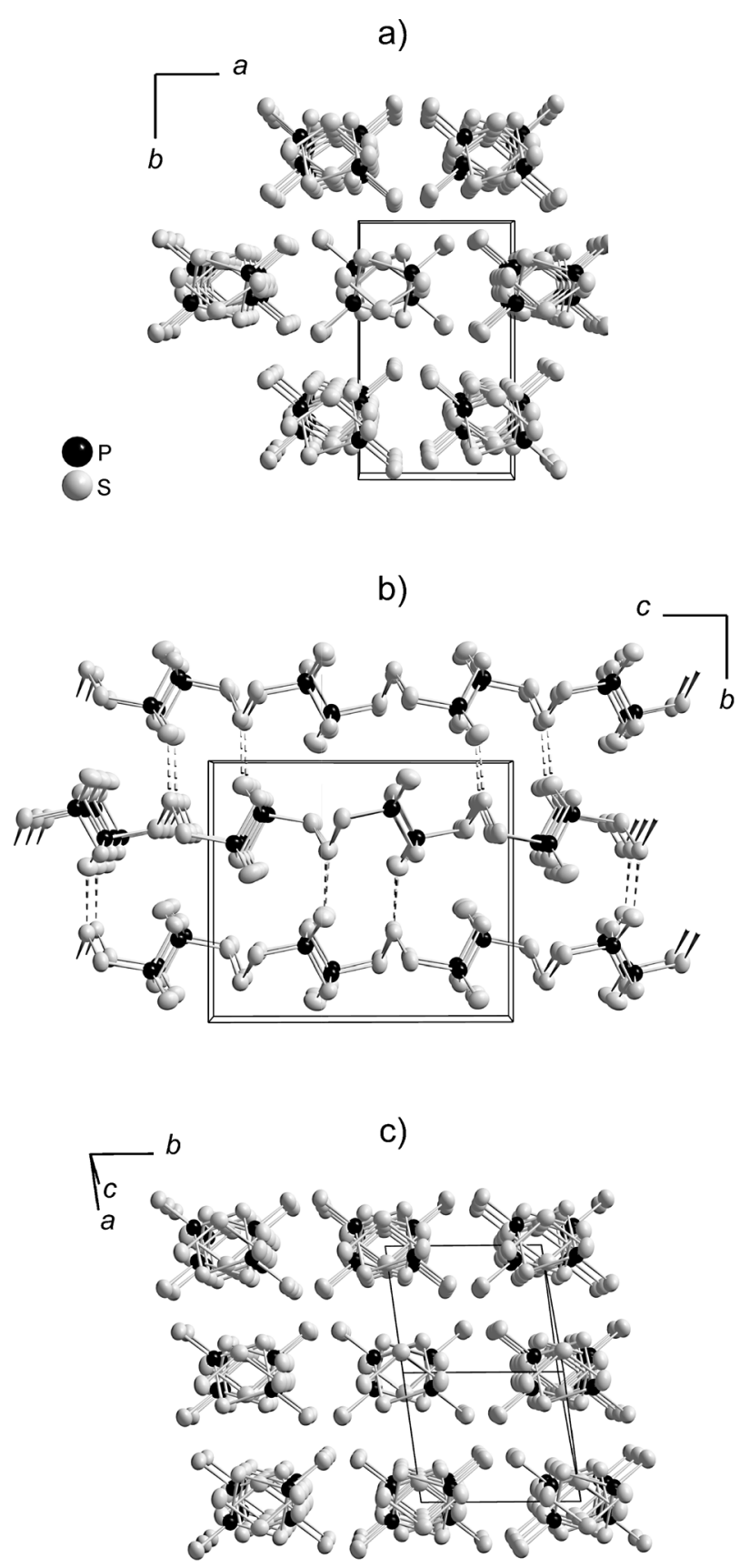

d)

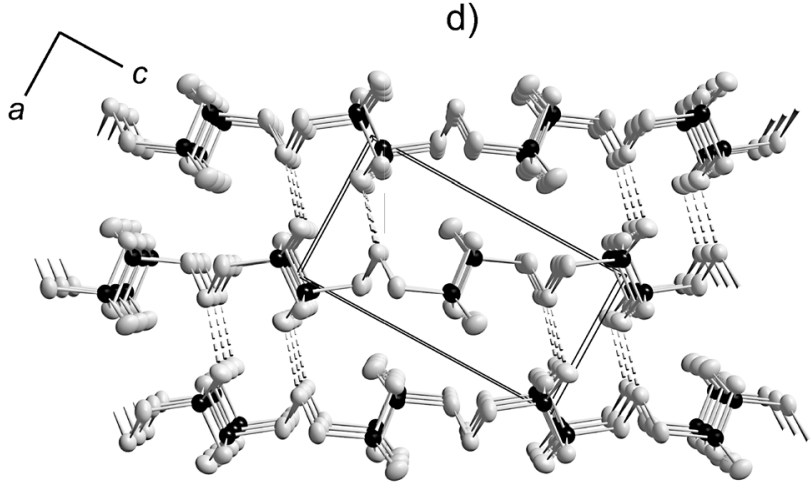


hexagonal packing of rods has the higher packing density. ${ }^{[13]}$ This deviation is due to a non-ideal packing of the onedimensional infinite phosphorus polysulfides or their deviations from an ideal rod-shape. Regardless of these differences in packing both modifications show a translational periodicity that differs for less than $0.1 \AA$; the translational units have a length of $d_{\text {mean }}=12.565 \AA$.

Our new synthesis route using catalytic amounts of anhydrous iron(III) chloride as mineralizer ${ }^{[14]}$ leads to a mixture of crystalline $\alpha-\mathrm{P}_{2} \mathrm{~S}_{7}$ and $\beta-\mathrm{P}_{2} \mathrm{~S}_{7}$. The synthesis without the $\mathrm{FeCl}_{3}$ catalyst yields solely a pure glass. The use of a mineralizing agent implies the formation of volatile gas-phase species which support the growth of crystalline material. The corresponding $\mathrm{X}$-ray powder diagram indicates a ratio of approximately 60:40 ( $\alpha: \beta)$ (see Supporting Information, Figure S1). The importance of the catalyst for the formation of a crystalline reaction product also becomes clear from thermal analyses. Thus, a broad endothermic peak at $288^{\circ} \mathrm{C}$ is visible only in the first heating cycle, see Supporting Information, Figure S3. Subsequent heating cycles do not show any thermal effects up to $400{ }^{\circ} \mathrm{C}$, indicating that no crystalline compound is present after the first melting process.

The ${ }^{31} \mathrm{P}$ magic angle spinning (MAS) NMR spectrum (Supporting Information, Figure S4 and Table S1) of the reaction product is in agreement with the X-ray diffraction data. Deconvolution reveals three signal pairs based on the peak intensities. With roughly $50 \%$ relative intensity the resonances at $\delta=60.1$ and $57.9 \mathrm{ppm}$ may be assigned to the $\alpha$ modification, whereas the pair $\delta=63.8$ and $54.0 \mathrm{ppm}$ (ca. $40 \%$ ) corresponds to $\beta-\mathrm{P}_{2} \mathrm{~S}_{7}$. The remaining pair $\delta=62.5$ and $57.4 \mathrm{ppm}$ (ca. $10 \%$ ) probably belongs to an impurity which was not detected by X-ray diffraction. A scanning electron microscopic (SEM) image illustrates the fibrous morphology of the phosphorus polysulfides (Figure 3 ).

The Raman spectrum of a mixture of $\alpha-\mathrm{P}_{2} \mathrm{~S}_{7}$ and $\beta-\mathrm{P}_{2} \mathrm{~S}_{7}$ shows a series of sharp resonances (Figure 4). It can be divided into three regions, namely the region $690-710 \mathrm{~cm}^{-1}$ corresponding to $\mathrm{P}-\mathrm{S}$ stretching vibrations of terminal

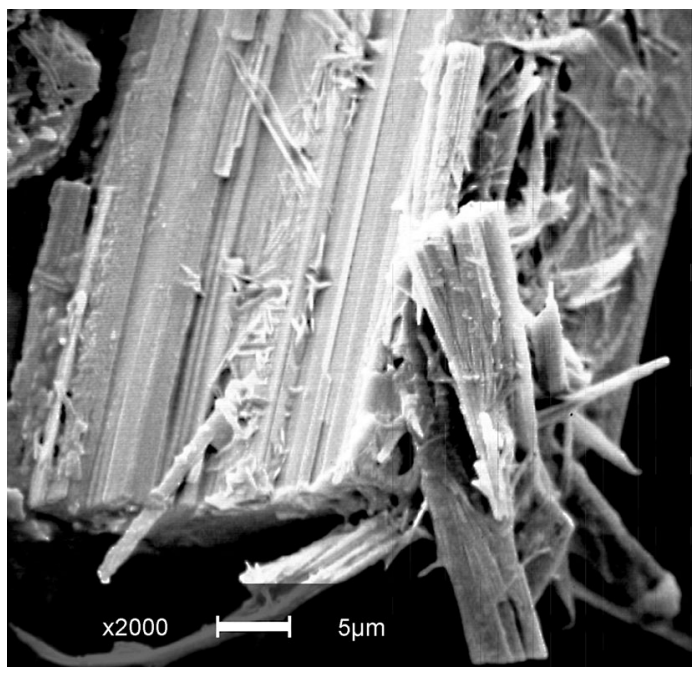

Figure 3. SEM image of a polycrystalline sample of the phosphorus polysulfides illustrating their fibrous morphology.

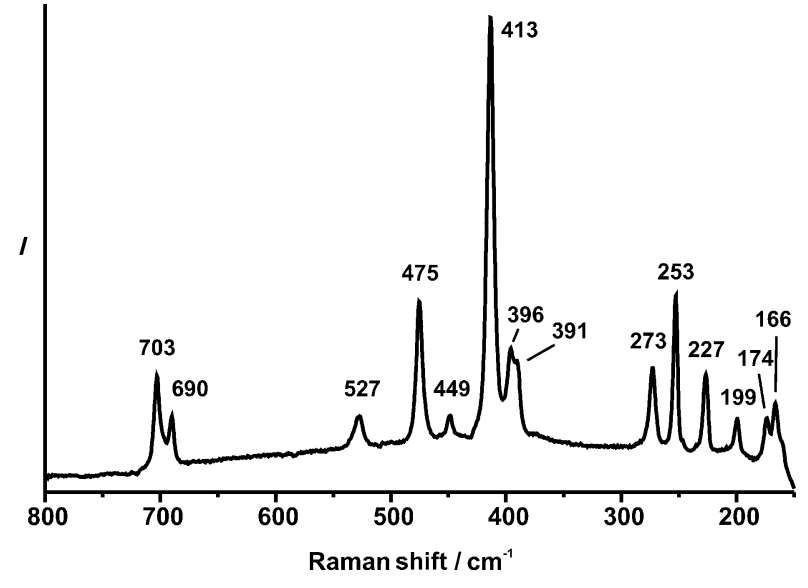

Figure 4. Raman spectrum of a mixture of $\alpha-P_{2} S_{7}$ and $\beta-P_{2} S_{7}$.

bonded sulfur atoms, the region $390-530 \mathrm{~cm}^{-1}$ corresponding to the remaining $\mathrm{P}-\mathrm{S}$ and $\mathrm{S}-\mathrm{S}$ stretching vibrations, and finally the deformation region from $160-275 \mathrm{~cm}^{-1}$. A tentative assignment of the stretching vibrations is based on comparison with the frequencies assigned for $\mathrm{K}_{2} \mathrm{P}_{2} \mathrm{~S}_{6}{ }^{[11 c]}: v\left(\mathrm{P}_{2} \mathrm{~S}_{2}\right.$-ring $)$ is observed at 413,396 , and $391 \mathrm{~cm}^{-1}$, the higher frequency bands at 449,475 , and $527 \mathrm{~cm}^{-1}$ must be due to vibrations of the bridging $\mathrm{S}_{3}$ unit. ${ }^{[15]}$ The measured frequencies (in $\mathrm{cm}^{-1}$ ) are: 703w, 690vw, 527vw, 475m, 449vw, 413vs, 396w, 391w(sh), 273w, $253 \mathrm{~m}, 227 \mathrm{w}, 199 \mathrm{vw}, 174 \mathrm{vw}$, and 166w. However, a final assignment of all observed frequencies is topic of a forthcoming study and needs sophisticated theoretical calculations.

The high temperature synthesis of $\mathrm{P}_{2} \mathrm{~S}_{7}$ from $\mathrm{P}_{4} \mathrm{~S}_{3}$ and elemental sulfur by catalytic amounts of $\mathrm{FeCl}_{3}$ shows up a new reaction pathway of phosphorus chalcogenides and metal halides. We recently observed the iron(III)-catalyzed formation of $\gamma-\mathrm{P}_{4} \mathrm{~S}_{6}$ in $\mathrm{CS}_{2}$ as a solvent, ${ }^{[16]}$ the reaction of $\mathrm{P}_{4} \mathrm{~S}_{10}$ with $\mathrm{TiCl}_{4}$ in solution results in the formation of $\left[\left(\mathrm{TiCl}_{2}\right)(1,3-\right.$ $\left.\left.\mathrm{P}_{2} \mathrm{~S}_{8}\right)\right]_{2} \cdot{ }^{[12]}$ In contrast, the cage molecules are preserved in adducts with $\mathrm{TaCl}_{5}{ }^{[17]}$ or even as co-crystals with $\mathrm{Ta}_{2} \mathrm{Cl}_{10}{ }^{[18]}$ when reactions are performed in solution. These findings imply that polymeric $\mathrm{P}_{2} \mathrm{~S}_{7}$ can be regarded as thermodynamically stable. Preliminary theoretical DFT investigations reveal a stabilization of about $(120 \pm 3) \mathrm{kJ} \mathrm{mol}^{-1}$ for both modifications in comparison to molar ratios of black $\mathrm{P}$ and $\mathrm{S}_{8}$ (see Supporting Information for details). Effects of the packing of the strands on the electronic structures are indicated by slight differences in energy and band structures. However, both, $\alpha-$ and $\beta-\mathrm{P}_{2} \mathrm{~S}_{7}$ are predicted to be indirect semiconductors with calculated electronic gaps $(2.0 \mathrm{eV})$ that are smaller than the measured optical bandgap of $2.55 \mathrm{eV}$ (see Supporting Information Figure S2). The mentioned model of bonding with polarized S-P bonds is confirmed by electron localization function (ELF) analysis (Supporting Information Figure S6) and calculated charges for $S^{\text {term }}(\mathrm{Q}=-0.89), \mathrm{S}^{\text {brid }}$ (type 1$)(\mathrm{Q}=$ $-0.57), S^{\text {brid }}$ (type 2) $(\mathrm{Q}=-0.21), \mathrm{S}^{\text {brid }}$ (type 3$)(\mathrm{Q}=0)$.

It becomes clear that the reactivity of the hard Lewis acidic electron-poor transition metals towards phosphorus and arsenic chalcogenide cages shows a much higher diversity than the electron-rich, soft Lewis acidic late transition metals $\mathrm{Cu}^{+}$and $\mathrm{Hg}^{2+}$. We usually find preservation or even formation 
of new cage molecules in high temperature reactions and in solution reactions instead of molecular transformations when halides of these metals are used as reaction partners. ${ }^{[19]}$

\section{Experimental Section}

The phosphorus polysulfides $\alpha-\mathrm{P}_{2} \mathrm{~S}_{7}$ and $\beta-\mathrm{P}_{2} \mathrm{~S}_{7}$ were obtained by heating a stoichiometric mixture of $\mathrm{P}_{4} \mathrm{~S}_{3}$ and sulfur to $250^{\circ} \mathrm{C}$ for 10 days in an evacuated silica ampoule using catalytic amounts of anhydrous $\mathrm{FeCl}_{3}$ as mineralizer. The yellow crystals are stable in air for several days; they are insoluble in $\mathrm{CS}_{2}$. The $\mathrm{X}$-ray powder diagram was recorded on a STOE STADIP diffractometer $\left(\mathrm{Cu} K_{\alpha 1}, \lambda=\right.$ $1.540598 \AA$ A ). Single-crystal X-ray measurements were performed on a STOE IPDS I diffractometer. ${ }^{[20]}$ The Raman spectrum was recorded on a Varian FT-Raman Module coupled to a Varian FTS 7000e spectrometer, equipped with a Nd:YAG laser (excitation wavelength $\lambda=1064 \mathrm{~nm}$ ) and a liquid-nitrogen cooled germanium detector. Polycrystalline samples were sealed in Duran glass capillaries of $1.5 \mathrm{~mm}$ outer diameter. The resolution was $2 \mathrm{~cm}^{-1}$. The spectrum was processed with the Varian Resolutions Pro software. ${ }^{[21]}$ The SEM image was taken with a Zeiss DSM 950 scanning electron microscope. Electronic energies and band structures were calculated with all electron codes ${ }^{[22]}$ applying DFT-GGA and B3LYP hybrid functionals. The electron localization function and Bader charges were computed with TOPOND 98. ${ }^{[22 c]}$

Received: May 20, 2011

Revised: July 27, 2011

Published online: September 26, 2011

Keywords: phosphorus - polymer - polysulfides .

structure elucidation $\cdot$ sulfur

[1] H. G. von Schnering, W. Hönle, Chem. Rev. 1988, 88, 243.

[2] a) J. Berzelius, Justus Liebigs Ann. Chem. 1843, 46, 251; b) A. Vos, E. H. Wiebenga, Acta Crystallogr. 1955, 8, 217; c) R. Blachnik, J. Matthiesen, A. Mueller, H. Nowottnick, H. Reuter, Z. Kristallogr. New Cryst. Struct. 1998, 213, 233.

[3] R. Blachnik, A. Hoppe, Z. Anorg. Allg. Chem. 1979, 457, 91.

[4] R. Boulouch, C. R. Hebd. Seances Acad. Sci. 1904, 138, 363.

[5] M. E. Jason, Inorg. Chem. 1997, 36, 2641.

[6] A. M. Griffin, P. C. Minshall, G. M. Sheldrick, J. Chem. Soc. Chem. Commun. 1976, 809.

[7] a) M. Miesel, H. Grunze, Z. Anorg. Allg. Chem. 1970, 373, 265; b) W. Bues, M. Somer, W. Brockner, Z. Anorg. Allg. Chem. 1981, 476, 153; c) J.-J. Barieux, M. C. Démarcq, J. Chem. Soc. Chem. Commun. 1982, 176; d) T. Bjorholm, H. J. Jacobsen, J. Am. Chem. Soc. 1991, 113, 27; e) R. Blachnik, U. Peukert, A. Czediwoda, B. Engelen, K. Boldt, Z. Anorg. Allg. Chem. 1995, $621,1637$.

[8] a) W. Kuchen, H. G. Beckers, Angew. Chem. 1959, 71, 163; b) K Moedritzer, J. R. Van Wazer, J. Inorg. Nucl. Chem. 1963, 25, 683 c) R. Förthmann, A. Schneider, Z. Phys. Chem. 1966, 49, 22; d) H. Vincent, Bull. Soc. Chim. Fr. 1972, 4517; e) J. Neels, A.-R Grimmer, M. Meisel, G.-U. Wolf, H. Jancke, Z. Anorg. Allg. Chem. 1987, 547, 83; f) R. Blachnik, U. Peukert, A. Czediwoda, B. Engelen, K. Boldt, Z. Anorg. Allg. Chem. 1995, 621, 1637.

[9] A. Stock, Ber. Dtsch. Chem. Ges. 1910, 43, 1223.

[10] M. C. Démarcq, Phosphorus Sulfur Relat. Elem. 1987, 33, 127.

[11] a) P. Toffoli, P. Khodadad, N. Rodier, Acta Crystallogr. Sect. B 1978, 34, 3561; b) C. Wibbelmann, W. Brockner, B. Eisenmann, H. Schäfer, Z. Naturforsch. B 1983, 38, 1575; c) W. Brockner, R. Becker, B. Eisenmann, H. Schäfer, Z. Anorg. Allg. Chem. 1985, $520,51$.

[12] D. Hoppe, A. Pfitzner, Z. Anorg. Allg. Chem. 2009, 635, 1986.
[13] M. O'Keeffe, S. Andersson, Acta Crystallogr. Sect. A 1977, 33, 914.

[14] a) H. Schäfer, Angew. Chem. 1976, 88, 775; Angew. Chem. Int. Ed. Engl. 1976, 15, 713; b) S. Lange, M. Bawohl, R. Weihrich, T. Nilges, Angew. Chem. 2008, 120, 5736; Angew. Chem. Int. Ed. 2008, 47, 5654.

[15] a) P. Boolchand, P. Chen, U. Vempati, J. Non-Cryst. Solids 2009, 355, 1773; b) L. Koudelka, M. Pisarčik, M. S. Gutenev, L. N. Blinov, J. Mater. Sci. Lett. 1989, 8, 933.

[16] T. Rödl, A. Pfitzner, Z. Anorg. Allg. Chem. 2011, 637, 1507.

[17] a) D. Hoppe, A. Pfitzner, Z. Naturforsch. B 2009, 64, 58; b) D. Hoppe, D. Schemmel, M. Schütz, A. Pfitzner, Chem. Eur. J. 2009, 15,7129 ; c) H. Nowottnick, K. Stumpf, R. Blachnik, H. Reuter, Z. Anorg. Allg. Chem. 1999, 625, 693.

[18] D. Hoppe, A. Pfitzner, Z. Anorg. Allg. Chem. 2006, 632, 1771.

[19] a) A. Pfitzner, S. Reiser, Inorg. Chem. 1999, 38, 2451; b) A. Pfitzner, Chem. Eur. J. 2000, 6, 1891; c) A. Pfitzner, S. Reiser, T. Nilges, Angew. Chem. 2000, 112, 4328; Angew. Chem. Int. Ed. 2000, 39, 4160; d) S. Reiser, G. Brunklaus, J. H. Hong, J. C. C. Chan, H. Eckert, A. Pfitzner, Chem. Eur. J. 2002, 8, 4228; e) T. Nilges, S. Reiser, A. Pfitzner, Z. Anorg. Allg. Chem. 2003, 629, 563 ; f) S. Nilges, T. Nilges, H. Haeuseler, A. Pfitzner, J. Mol. Struct. 2004, 706, 89; g) M. F. Bräu, A. Pfitzner, Angew. Chem. 2006, 118, 4576; Angew. Chem. Int. Ed. 2006, 45, 4464; h) M. F. Bräu, A. Pfitzner, Z. Anorg. Allg. Chem. 2007, 633, 935; i) J. Wachter, Coord. Chem. Rev. 2010, 254, 2078; j) A. Biegerl, C. Gröger, H. R. Kalbitzer, A. Pfitzner, J. Wachter, R. Weihrich, M. Zabel, J. Solid State Chem. 2011, 184, 1719.

[20] X-ray structure analysis and crystallographic data for $\alpha-\mathrm{P}_{2} \mathrm{~S}_{7}$ : $M_{\mathrm{r}}=286.36 \mathrm{~g} \mathrm{~mol}^{-1}$, STOE IPDS, $T=296(2) \mathrm{K}, \operatorname{MoK}_{a}(\lambda=$ $0.71073 \AA$ ), $2 \theta_{\max }=50.30^{\circ}$, crystal size $0.15 \times 0.03 \times 0.02 \mathrm{~mm}^{3}$, monoclinic, space group $P 2_{1} / c$ (No.14), $a=6.526(2), b=$ 10.817(4), $c=12.580(3) \AA, \beta=93.24(2)^{\circ}, V=886.6(4) \AA^{3}$ (lattice constants refined from powder data (WinXPOW, Stoe \& Cie GmbH, Darmstadt, 2000), transmission geometry, STOE STADI P, $\left.\mathrm{Cu} K_{\mathrm{\alpha} 1}(\lambda=1.540598 \AA)\right), Z=4, \rho_{\text {calcd }}=2.145 \mathrm{~g} \mathrm{~cm}^{-3}$, $\mu\left(\mathrm{MoK}_{\alpha}\right)=2.050 \mathrm{~mm}^{-1}, 8088$ measured reflections, 1544 independent reflections, $R_{\text {int }}=0.0643$, numerical absorption correction (X-RED32, Stoe \& Cie GmbH, Darmstadt, 2004) after optimizing the shape of the crystal (X-SHAPE, Stoe \& Cie $\mathrm{GmbH}$, Darmstadt, 1999), structure solution by direct methods (SIR2004, M. C. Burla, C. Rocco, M. Camalli, B. Benedetta, G. L. Cascarano, L. De Caro, C. Giacovazzo, G. Polidori, R. Spagna, J. Appl. Crystallogr. 2005, 38, 381), structure refinement on $F^{2}$ (SHELXL, G. M. Sheldrick, Acta Crystallogr. Sect. A 2008, 64,112), 82 parameters, $R_{1}(I \geq 2 \sigma(I))=0.0303, w R_{2}(I \geq 2 \sigma(I))=$ $0.0470, R_{1}$ (all data) $=0.0693, w R_{2}($ all data $)=0.0529, \mathrm{GooF}=$ 0.836 , residual electron density $=0.280 /-0.278 \mathrm{e}^{-3}$. $\mathrm{X}$-ray structure analysis and crystallographic data for $\beta-\mathrm{P}_{2} \mathrm{~S}_{7}$ : $M_{\mathrm{r}}=286.36 \mathrm{~g} \mathrm{~mol}^{-1}$, STOE IPDS, $T=296(2) \mathrm{K}, \operatorname{MoK}_{\alpha}(\lambda=$ $0.71073 \AA$ ), $2 \theta_{\max }=51.58^{\circ}$, crystal size $0.24 \times 0.05 \times 0.04 \mathrm{~mm}^{3}$, triclinic, space group $P \overline{1}$ (No.2), $a=6.032(3), b=6.512(2), c=$ $11.095(5) \AA, \quad \alpha=82.62(4), \quad \beta=89.20(5), \quad \gamma=85.28(4)^{\circ}, \quad V=$ 430.7(3) $\AA^{3}$ (lattice constants refined from powder data (WinXPOW), transmission geometry, STOE STADI P), $Z=2, \rho_{\text {calcd }}=$ $2.208 \mathrm{~g} \mathrm{~cm}^{-3}, \mu\left(\mathrm{MoK}_{a}\right)=2.110 \mathrm{~mm}^{-1}, 6122$ measured reflections, 1557 independent reflections, $R_{\text {int }}=0.0240$, numerical absorption correction (X-RED) after optimizing the shape of the crystal (X-SHAPE), structure solution by direct methods (SIR2004), refinement on $F^{2}$ (SHELXL), 82 parameters, $R_{1}$ $(I \geq 2 \sigma(I))=0.0223, w R_{2} \quad(I \geq 2 \sigma(I))=0.0477, R_{1} \quad($ all data $)=$ $0.0294, w R_{2}$ (all data) $=0.0490, \mathrm{GooF}=0.974$, residual electron density $=0.445 /-0.192 \mathrm{e}^{-3}$. Further details on the crystal structure investigation may be obtained from the Fachinformationszentrum Karlsruhe, 76344 Eggenstein-Leopoldshafen, Germany (fax: (+49)7247-808-666; e-mail: crysdata@fiz-karlsru- 


\section{Communications}

he.de), on quoting the depository numbers CSD-423061 ( $\alpha$ $\left.\mathrm{P}_{2} \mathrm{~S}_{7}\right)$, and CSD-423062 $\left(\beta-\mathrm{P}_{2} \mathrm{~S}_{7}\right)$.

[21] Resolutions Pro Software, Molecular Spectroscopy Solutions, Varian Inc. Version 4.1.0.101, 2006.

[22] a) K. Koepernik, H. Eschrig, Phys. Rev. B 1999, 59, 1743; b) R. Dovesi, V. R. Saunders, C. Roetti, R. Orlando, C. M. Zicovich-
Wilson, F. Pascale, B. Civalleri, K. Doll, N. M. Harrison, I. J. Bush, P. D'Arco, M. Llunell, CRYSTAL09 User's Manual. University of Torino, Torino, 2009; c) C. Gatti, Topond98, user's manual, Milano, 1998. 